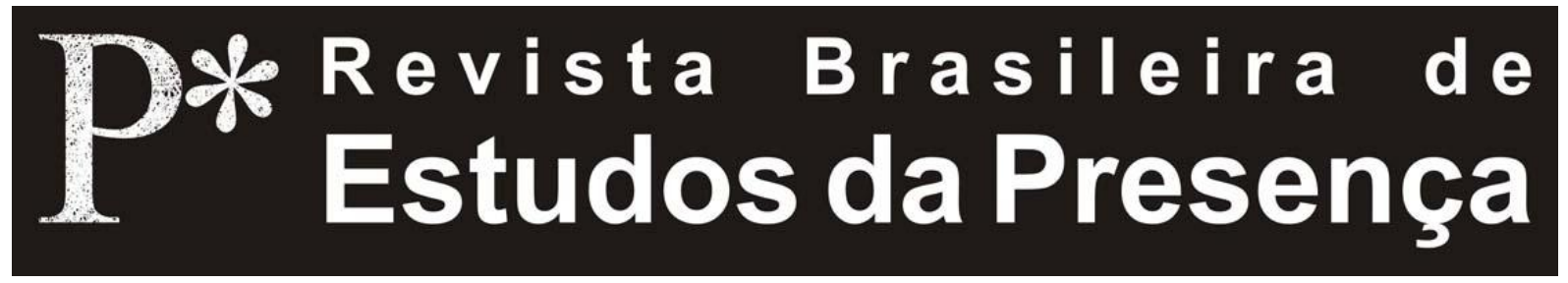

DOI - http://dx.doi.org/10.1590/2237-266022494

ISSN 2237-2660

\title{
O Laboratório do Dramaturg e os Estudos de Genética Teatral: experimentos
}

\author{
Maria de Lourdes Rabetti \\ Universidade Federal do Estado do Rio de Janeiro - UNIRIO
}

RESUMO - O Laboratório do Dramaturg e os Estudos de Genética Teatral: experimentos - $\mathrm{O}$ estudo situa-se no campo da Genética Teatral e discute a presença do dramaturg em ação. Avalia pertinências e singularidades do processo de migrações textuais em direção à cena teatral decorrentes de exercícios combinados de tradução e dramaturgismo, desenvolvidos entre os anos de 1985 e 1991 no âmbito da Companhia de Encenação Teatral da cidade do Rio de Janeiro. Atualiza e comenta experiência acumulada no quadro da criação de alguns espetáculos resultantes de longos e continuados processos de construção. Teoricamente, pois, a proposta é a de compreender a Genética Teatral com os olhos do dramaturgista, historiador do teatro.

Palavras-chave: História. Genética Teatral. Dramaturgismo. Bricolagem. Escrita Cênica.

ABSTRACT - The Laboratory of the Dramaturge and the
Studies on Theatrical Genetics: experiments - The study is in
the field of Theatrical Genetics and deals with the presence of the
dramaturge in action. It assesses the relevance and uniqueness of
the process of textual migration toward theater scene due to the
combined exercises of translation and dramaturgy developed
between 1985 and 1991 by the Companhia de Encenação Teatral of
the city of Rio de Janeiro. It updates and comments on accumulated
experience in the creation of some shows as a result of the long and Maria de Lourdes Rabetti, O Laboratório do Dramaturg e os Estudos de Genética Teatral: experimentos R.bras.est.pres., Porto Alegre, v.1, n.2, p. 443-458, jul./dez., 2011.

Disponível em http://www.seer.ufrgs.br/presenca 
continuous process of construction. Theoretically, therefore, because the proposal is to understand Theatrical Genetics through the eyes of the dramaturge, the historian of theater.

Keywords: History. Theatrical Genetics. Dramaturgy. Bricolage. Theatrical Writing.

RÉSUMÉ - Le Laboratoire du Dramaturge et d'Études Génétiques Théâtrales: expériences - L'étude se situe dans le domaine de la génétique théâtrale et discute la présence du dramaturge en action. Elle évalue la pertinence et l'originalité du processus de migration textuelle vers la scène théâtral résultant d'exercices conjoints de traduction et de dramaturgie développés entre 1985 et 1991, sous la mise en scène de la Compagnie théâtrale de la ville de Rio de Janeiro. Elle met à jour et commente l'expérience accumulée au sein de la création de quelques spectacles résultant d'un long et constant processus de construction. Théoriquement, la proposition est de comprendre la génétique théâtrale avec les yeux du dramaturge, historien du théâtre.

Mots-clés: Histoire. Génétique Théâtrale. Dramaturgie. Bricolagem. Écrit Scénique.

\section{Apresentação $^{1}$}

Entre os anos de 1985 e 1991 a Companhia de Encenação Teatral da cidade do Rio de Janeiro desenvolveu trabalhos regulares com textos clássicos, de porte, alguns inéditos em versão brasileira, escolhidos e trabalhados na perspectiva do encontro ou construção de uma linguagem cênica contemporânea, que atendesse às inquietações de seus membros coordenadores e contribuísse para demarcar sua presença na cidade daqueles anos. Ao mesmo tempo, esperava-se que os componentes do grupo, que se pretendia reunir em caráter estável, encontrassem, no seio da Companhia e em suas experiências de cena, espaço de formação. Naquele âmbito, teve presença permanente e função de destaque o trabalho de dramaturgismo que, voltado para a elaboração de uma linguagem de cena por meio da qual pretendia contribuir para a formação de atores e criação de público, viu-se às voltas com a escolha de textos a montar, alguns deles, inclusive, a traduzir, e sobre os quais intervir por determinação das questões da cena. Num período de seis anos foram elaborados sete espetáculos resultantes de

Maria de Lourdes Rabetti, O Laboratório do Dramaturg e os Estudos de Genética Teatral: experimentos R.bras.est.pres., Porto Alegre, v.1, n.2, p. 443-458, jul./dez., 2011. 
longos processos preparatórios, que incluíram, simultaneamente, resgate e intervenção em textos matriciais que, exatamente na medida de sua densidade, se colocaram favoravelmente a serviço da cena, nela encontrando coautorias. $\mathrm{O}$ presente texto pretende apontar para o processo de migrações textuais ligado ao exercício do tradutor e do dramaturg, que, em sobreposição ou não, pode suscitar matizes singulares nos estudos de genética teatral.

A Companhia de Encenação Teatral, criada na cidade do Rio de Janeiro, ao final de 1985 e instituída juridicamente em 1987, teve como núcleo fundador o diretor Moacyr Góes, os atores Léon Góes e Floriano Peixoto, o músico Mario Vaz de Mello e Maria de Lourdes Rabetti (Beti Rabetti), dramaturgista. Os primeiros trabalhos - Nosferatu - sinfonia de vida e morte e Woyzeck ${ }^{2}$ - foram elaborados em salas de ensaio privadas e os espetáculos resultantes ocuparam espaços então considerados alternativos na cidade do Rio: o Teatro Experimental Cacilda Becker, no Catete, do Serviço Nacional de Teatro (hoje Fundação Nacional de Artes, ligada ao Ministério da Cultura) e o então Galpão Sérgio Porto (hoje Espaço Cultural Municipal Sérgio Porto), no bairro do Humaitá. Para os dois primeiros trabalhos, uma recepção modesta, mas crescente e críticas jornalísticas negativas no primeiro caso, e que rigorosamente ignoraram a experiência do segundo. Para o terceiro espetáculo da Companhia, Baal ${ }^{3}$, de 1988/89 os trabalhos foram longamente preparados por vários meses e apresentados na sala de ensaios (para dança e teatro) localizada nos fundos do Teatro Villa-Lobos, em Copacabana, também administrado pela Prefeitura da cidade. O longo trabalho representou um marco no trajeto do grupo, que se acrescera com a chegada de Samuel Abrantes, para figurinos e adereços, e da produtora Julia Valladares: pelo tempo de sua elaboração; pela intervenção cênica na sala de ensaios que acabou por abrigar o espetáculo apresentado ao público; pelo reconhecimento de crítica e de público (que desde então passou a se configurar, pela assiduidade e pela participação ativa em debates e outros eventos paralelos

Maria de Lourdes Rabetti, O Laboratório do Dramaturg e os Estudos de Genética Teatral: experimentos R.bras.est.pres., Porto Alegre, v.1, n.2, p. 443-458, jul./dez., 2011. 
da Companhia, como público engajado, que em boa parte acompanhou a série sucessiva de trabalhos); pela curiosidade frente à clara entrada em cena do dramaturg nos palcos do país e que no processo criativo de Baal teve, de fato, presença bastante acentuada ${ }^{4}$. O número de críticas jornalísticas de qualidade e tom variados, a visita de artistas profissionais e acadêmicos importantes, inclusive da vizinha cidade de São Paulo, as discussões continuadas, terminaram por evidenciar a presença de um grupo de razoável constância (de produção espetacular e de investimento na equipe) e com qualidade meritória.

O fato é que a Companhia de Encenação Teatral, que fizera torcer o nariz de um certo setor de crítica tradicional - que por vezes questionava sua insistência em fazer (e dizer fazer) pesquisa da cena teatral e que não poucas vezes parecia comparecer aos espetáculos exclusivamente por exigência de jornais e de mercado de Nosferatu a Os gigantes da montanha ${ }^{5}$, quando se dissolveu, em 1991 - ocupou um lugar importante de experiência e de pensamento sobre a cena, impresso no seu processo de construção e persistente no seu resultado levado a público por algumas cidades do país onde foi convidada a apresentar seus espetáculos. E legou memórias de uma cena artística intensamente teatralizada, disponibilizou textos inéditos para ela traduzidos e por ela discutidos, enorme contribuição para a questão crucial das relações entre teoria e prática na construção da obra espetacular, além de um novo espaço teatral (o que não é nada pouco) para a cidade do Rio: o Espaço III - VillaLobos, a antiga sala de ensaios, nos fundos do grande edifício da Avenida Princesa Isabel, transformou-se em regular sala de espetáculos da cidade. E consagrou profissionais atuantes até os dias de hoje, reconhecidos em diferentes espaços artísticos e culturais: desde a universidade, até o cinema e o teatro.

Mas, não é por motivos de consagração que o intenso e continuado trabalho realizado durante seis anos pela Companhia de Encenação Teatral e o trabalho de dramaturgismo no Brasil, por meio dela revelado e reconhecido, interessa à discussão. É porque na sua duração - nada desprezível para um grupo teatral

Maria de Lourdes Rabetti, O Laboratório do Dramaturg e os Estudos de Genética Teatral: experimentos R.bras.est.pres., Porto Alegre, v.1, n.2, p. 443-458, jul./dez., 2011. 
brasileiro na segunda metade dos anos 1980 - destacou, com vigor e por vezes com demasiada insistência, a importância da presença de um pensamento sobre a cena (e sobre o teatro), na cena, enquanto esta ocorre; o que acreditamos interessar ao conjunto das questões propostas pela Genética Teatral, especialmente no que tange ao argumento Do laboratório à escrita da cena ${ }^{6}$, na medida em que aquelas cenas teriam incorporado à sua escrita questões laboratoriais do dramaturgismo em ação, expressas, assim, como componentes artísticos, questões encenadas, por assim dizer.

\section{O Dramaturgismo como Bricolagem}

Compreendo aquela experiência teatral como proposição, experimentação e percepção, em espaço formal e artístico, de um pensamento concreto que ia se estabelecendo ao longo do tempo e que, por continuado remanejamento de unidades artísticas compositivas desde adereços e vestimentas a fragmentos textuais escritos - ia formando um acervo de elementos gerados pelos trabalhos das cenas que, assim, mantinham-se em conversação. Claramente, tomo de empréstimo, para falar deste procedimento, a noção de bricolagem, bastante apropriada, como sabemos, a formas de pensamento concreto, como ensina Lévi-Strauss (1970) e, em sua trilha, Certeau (1999), e como acredito poder compreender a reflexão do dramaturg posta em cena, auxiliada também por algumas Sobreposições de Bene e Deleuze (1979).

Emblema de uma linguagem em processo de construção, do qual os espetáculos consideravam-se momentos emergenciais, era o personagem AtorCharlatão: oriundo da cena, foi o representante por excelência do grupo teatral e do pensamento que vinha elaborando a respeito do teatro. Como personagem emergente da cena e sucessivamente adequado à série dos espetáculos elaborados, desempenhava sempre uma mesma função basilar, a de narrador - condutor comentador do espetáculo, fosse ele constituído de forma inteiramente autônoma - brotando inteiramente no canteiro de obras da cena - fosse composto por

Maria de Lourdes Rabetti, O Laboratório do Dramaturg e os Estudos de Genética Teatral: experimentos R.bras.est.pres., Porto Alegre, v.1, n.2, p. 443-458, jul./dez., 2011. 
sobreposição a algum outro personagem presente em textos matriciais, como ocorreu na maior parte dos casos.

$\mathrm{O}$ que se verifica aqui é um processo integrado de construção de espetáculos, que dialogam e interagem, por meio de um procedimento ditado pelo exercício de bricolagem e sobreposições, gerador e reutilizador de dados mantidos em repertório cênico, e, simultaneamente, combinados ainda com textos dramáticos colhidos no repertório mais amplo da dramaturgia universal. Peças dramáticas compreendidas como partes importantes de um empreendimento cênico de mais longa duração e, do mesmo modo, momento singular e parte interessada no desenvolvimento de um pensamento sobre o teatro por meio da cena espetacular.

\section{O Percurso em Vaivém: desafios da genética teatral}

Resulta destas sobreposições e combinações, um exercício migratório entre texto e cena que pouco se percebe como percurso de dimensões lineares, e que faz do local de origem não um lugar inaugural, mas apenas dispositivo para atuação. Trata-se aqui de pensar estruturas simultâneas sobre as quais, ou em meio às quais, traçar sobretudo círculos e vaivéns exaustivos. $\mathrm{O}$ meio da cena é o lugar de onde emerge o traço diferenciado do dramaturgismo; presença pensante por excelência no seio da obra de arte em construção a colocar permanentemente tudo em questão; a fragilizar, portanto, também os caminhos migratórios mais comuns do texto à cena.

Após a experiência cênica de tratamento poético e sublime do tema de Nosferatu, Woyzeck, de Georg Büchner, atendia aos anseios do grupo inicialmente pela potência de teatralidade decorrente de sua estrutura aberta, possibilitando intervenções destemidas na obra dramática por sugestão e autorização do próprio autor dramático, por assim dizer. O tema do herói humilhado, deslocado e tripudiado, marionete sempre fora de lugar atendia ainda à necessidade de experimentar cenicamente uma linguagem mais humana, beirando a condição grotesca. Com sete meses de elaboração, o espetáculo foi 
apresentado ao público em abril de 1987, ficando em cartaz por três meses.

Traduzida de versão francesa, que apresentava na abertura do episódio da feira "Barracas e Luzes. A Multidão", a versão cênica prestou-se a enfatizar os caminhos perdidos do herói esfarrapado, suas idas e vindas, num caminho que diretor e dramaturgista entendiam circular, ou melhor, ou de repisadas, sincopadas e abruptas, sempre sobre um mesmo lugar. $\mathrm{O}$ traçado da cena conduziu o encerramento do espetáculo, após a morte do herói emborcado num barril, ao mesmo fragmento textual büchneriano utilizado para a abertura da versão francesa matricial.

Cenicamente, o charlatão da barraca da feira, que com um mesmo fragmento anunciava e encerrava $o$ espetáculo, poderia simultaneamente fazer duplicar os sentidos originais, suficientemente fissurados e disponíveis, e falar, com a mesma fala, sobre a arte do Teatro. Com a reiteração do episódio da feira, em chamamento aos espectadores, e com a amplificação do trabalho atorial, pela forma esgarçada e quase altissonante, como que proferia exatamente a idêntica passagem do texto matricial, em tons e ritmos alargados, acompanhados de ações corporais contrastadas, provocadoras de desequilíbrio sobre o público, o terrível protagonista cênico, recém-nomeado Ator-Charlatão remetia diretamente ao espetáculo em curso; assim como ao anterior, Nosferatu, em que o mesmo ator, Leon Góes, com o mesmo casaco e alguns componentes interpretativos fundamentais dos loucos de Stoker, Murnau e Herzog, conduzia boa parte daquela sinfonia de vida e morte.

\section{Sobreposições: personagens textuais ou personagens cênicos?}

O que se quer destacar, para fins da discussão a respeito do laboratório do dramaturg, em suas ações sobre caminhos entre texto e cena, é que a partir de uma sobreposição ao personagem matricial - periférico nas tramas originais - um novo personagem, o do AtorCharlatão, começara a se compor; e ele passará por um

Maria de Lourdes Rabetti, O Laboratório do Dramaturg e os Estudos de Genética Teatral: experimentos R.bras.est.pres., Porto Alegre, v.1, n.2, p. 443-458, jul./dez., 2011. 
longo processo de elaboração que o deslocará de sua original tendência periférica para o centro da cena, presença crucial em todos os espetáculos elaborados pela Companhia de Encenação Teatral desde então:

O charlatão - Senhoras, Senhores! Vejam a criatura tal como deus a fez: não é nada, absolutamente nada! Agora vejam a potência da arte: ela se levanta, ela anda, ela veste paletó e calças e tem uma espada. [...] A representação vai começar. On commence au commencement $d u$ commencement. Vocês vão ver aquilo que vocês vão ver.

A teatralidade enfatizada pela cena que em abertura e em fechamento colocava, afinal, o teatro dentro do teatro compactuava a favor da escrita cênica que almejara exasperação e concentração: escolhendo alguns dos episódios de Büchner e dirigindo o alvo para a discussão sobre o teatro, sugerindo a prioridade da construção cênica sobre a narrativa matricial construída por episódios desordenados, o laboratório do dramaturg experimentava outras trilhas entre texto e cena. Pode-se dizer, portanto, que o belíssimo texto dramático fragmentário de Büchner apresentou-se ao laboratório do dramaturgista como mecanismo potente e limite criador diante do qual a intrincada narrativa do trajeto convulso de Woyzeck não bastaria para a elaboração e implementação de um pensamento sobre o teatro na cena, qualquer que fosse a ordem escolhida para a apresentação dos episódios. A história de Woyzeck se encerra quando se entrega ao abismo e morre chafurdado no grande barril. A história da cena que, para além de reconstruir essa narrativa, pretendia apontar para a construção cênica de um pensamento necessitou, para além de toda teatralidade disponibilizada pelo texto original, repetir uma mesma cena matriz, mas para abrir e fechar o espetáculo de forma absolutamente idêntica. E nesta identidade discutir a construção artística e a representação: on commence au commencement $d u$ commencement. Ao fim de um espetáculo, continua o teatro.

Em Baal, de Brecht, 1988/89, este mesmo charlatão se reconstruiu no personagem $O$ Ator,

Maria de Lourdes Rabetti, O Laboratório do Dramaturg e os Estudos de Genética Teatral: experimentos R.bras.est.pres., Porto Alegre, v.1, n.2, p. 443-458, jul./dez., 2011. 
novamente trabalhado por Léon Góes. $\mathrm{O}$ texto, de juventude, de Brecht interessava a aquela etapa do percurso do grupo porque equilibrava, em cenas e em estrutura de personagens, dimensões estupendamente sublimes e condições de heróis chafurdados na lama, nos prostíbulos, soterrados, bêbados de vinho e poesia, e sem saída. O personagem Baal em cena, interpretado por um já renomado ator, José de Abreu, permaneceu nos contornos do texto dramático original e o trabalho cênico maior foi o de garantir à atuação a tranquilidade de se alojar sem medo nos largos veios poéticos da linguagem brechtiana que a constituía. No entanto, a linguagem geral da cena pretendeu continuar discutindo o teatro, seus limites e suas impossibilidades em meio à narração desta nova e boa história. Para tanto, dentre outros recursos, reinstalou na cena seu personagem condutor, construído agora especialmente para a contraposição ao lirismo de pés na lama do herói Baal: uma figura de Ator por excelência, dono da cena, foi inteiramente trabalhada em termos de ideário e de técnicas - nas informações e nas discussões em âmbito de commedia dell'arte.

Assim incorporado à narrativa cênica espetacular que reconstruiu a narrativa brechtiana, este personagem atuou paralelamente à atuação lírica de Baal, produzindo cenas de inversão, de rebaixamento, em dimensões de linguagem corpórea dançante e sinuosamente verbal, a proferir sons onomatopaicos rebaixadores, por vezes, verso a verso, após cada poético pronunciamento de um brechtiano Baal enlevado.

Desconstrutor permanente, o Ator entrou em cena pela figura do personagem mendigo de Brecht; contracenou intensamente com os demais personagens de modo mais contundente, com Baal -, e, a todo instante evidenciava a existência do espetáculo como construção em ato, apontando para várias direções; questionava a linguagem da cena no momento mesmo em que ela ocorria, sem impedir, no entanto, que o lirismo do jovem Brecht acabasse ocupando espaços inesperados, para todos. O crítico do Jornal do Brasil à época, Macksen Luis, ao comentar o espetáculo Baal, justamente ao refazer o trajeto do texto à cena, considerou a presença do

Maria de Lourdes Rabetti, O Laboratório do Dramaturg e os Estudos de Genética Teatral: experimentos R.bras.est.pres., Porto Alegre, v.1, n.2, p. 443-458, jul./dez., 2011. 
Ator - na cena do jovem Brecht de 1918 - um narrador brechtiano avant la lettre. Sim, pode-se dizer, um personagem extraído da história em cena (o mendigo), e também criado pela história $d a$ cena, que dele faz seu condutor. Portava a meia-máscara facial, detinha um bastão e percorria todos os espaços com constância ameaçadora, em movimentos e danças suavemente femininas (tinha o dorso nu e usava um saiote branco e suave até os pés) emitindo sons onomatopaicos graves, num grammelot paródia, ridículo e ferino com o qual detonava os versos mais belos de um Baal enlevado de paisagem e de vinho: frase a frase, som a som, tom a tom, conduzindo o espetáculo ao rés do chão, à estatura dos homens comuns:

E o amor é quando se deixa o braço nu mergulhado na água dum lago, com algas entre os dedos. É como a tempestade, diante da qual a árvore embriagada começa a cantar rangendo, a árvore sobre a qual cavalga o vento selvagem. É como beber vinho saboroso num dia muito quente, e o vinho penetrar no corpo dela muito fresco e em todos os poros da pele, suave como plantas ao vento são os membros, e a força do embate que a faz ceder é como voar na tormenta e o seu corpo agitando-se sob o teu é como um cascalho de um rio.

Expansão e concisão, lirismo e baixo corpóreo grotesco, público sentado no centro, em cadeiras giratórias. Ao seu redor cena ininterruptamente ocupada pelo texto de Brecht montado e desmontado num continuum, sem intervalos e sem entradas e saídas de atores: todos estavam presos à cena, e sem saída. $\mathrm{Na}$ conversação entre o texto do jovem Brecht e a cena teatral de uma companhia teatral em formação na cidade do Rio de Janeiro, um único movimento central fez pulsar continuadamente o jorro poético desmedido do texto e incisividade da concretude da cena, atorial e espacial. Nenhuma perspectiva; texto e cena em confronto de planaridades e sobreposições. Este foi mais um laboratório de invenções em meio ao qual o trabalho do dramaturg não realizou o trajeto tradicional e linear do texto à cena. Como sugeriu o crítico, insinuou-se mesmo um caminha inverso. E, então, tal como se dizia no

Maria de Lourdes Rabetti, O Laboratório do Dramaturg e os Estudos de Genética Teatral: experimentos R.bras.est.pres., Porto Alegre, v.1, n.2, p. 443-458, jul./dez., 2011. 
Programa da Peça dedicada a Luiz Antonio Martinez Corrêa, morto em 1987, brutalmente assassinado em sua casa, às vésperas do Natal:

\begin{abstract}
Vento:
$\mathrm{Na}$ dimensão devoradora da linguagem Baal-Brecht de 1918, a vertigem do lirismo, rasgada pelo cômico demolidor que "corrige" (comenta?) a própria embriaguez: o limite do riso mais largo é o ranger dos dentes.
\end{abstract}

\title{
O Personagem é a Palavra
}

A trágica história do Doutor Fausto ${ }^{7}$, de Marlowe, apresentou-se em 1989 como exigência, já anunciada durante a montagem de Baal, de bem maior exploração dos domínios da palavra encenada. E como ousadia de pensar na hipótese de uma palavra ainda capaz de instaurar a cena do teatro na contemporaneidade.

Em Marlowe, a desmedida do herói trágico, entre Idade Média e início de Era Moderna, passa pela abnorme sede de beleza e de conhecimento, intrincada entre o poder da imagem (Helena é uma imagem, só uma imagem) e o da palavra, que o (nos) constitui, pela qual Fausto já é responsável, e de que é vítima. As exigências da cena em busca de sua linguagem voltaram-se, como sempre, para a expressão de um pensamento sobre teatro a que se alia agora um dado, por assim dizer, de economia do grupo, ditado por necessidades sensíveis de formação atorial no domínio da palavra feita voz, palavra proferida. As orientações vinham da linguagem cênica: seu pensamento, seus meios para trabalhá-lo concretamente em seus elementos cruciais: as vozes dos atores com seus personagens. E o velho personagem cênico, nascido do laboratório do dramaturgismo em seu tratamento de textos matriciais, o não mais tão novo personagem $O$ Ator, sempre condutor dos sentidos e dos caminhos teatrais abraçados pela Companhia de Encenação, aqui entra em jogo como um arquicharlatão em vestes de Mefistófeles.

Não se possuía até então uma versão brasileira da peça, em seus possíveis cinco atos, de integridade tão discutida, pela sugerida interpolação de atos grotescos, de

Maria de Lourdes Rabetti, O Laboratório do Dramaturg e os Estudos de Genética Teatral: experimentos R.bras.est.pres., Porto Alegre, v.1, n.2, p. 443-458, jul./dez., 2011. 
baixo cômico, com atos de elevada tragicidade. Optou-se por trabalhar com a versão em cinco atos, da tradução italiana em prosa de Andreoni D'Ovidio, pela intensa e larga exercitação atorial que o texto permitia, ditada por caudaloso volume de palavras, pelo jogo das aproximações de contrários a que o texto de Marlowe se abria. Aglutinando exercício de tradução e de dramatugismo, traduzir foi lento e caprichoso movimento paulatino, simultâneo ao processo de construção do texto cênico. Seus traços indicavam idas e vindas provocadas pelos experimentos da cena em que a palavra escrita era, concomitantemente, voz dos atores, em modulagens advindas da imbricação entre texto impresso e texto da cena, expressivo de todas as dificuldades atoriais em formação e do próprio exercício do dramaturgismo e da encenação frente a texto de tal porte. Fato é que este procedimento de tradução, em movimento acoplado à construção da cena e intermediado pelas questões do dramaturg e do encenador, sempre interessadas em empreender cenicamente um pensamento concreto sobre a cena, tornou-se marco definidor do inteiro espetáculo teatral.

Foi assim que Fausto, interpretado por Floriano Peixoto, sob o comando do Ator/Mefistófeles/Léon Góes, encontrou-se solitário; no centro da cena, viu-se obrigado a ler inteiramente seu texto, que encontrou impresso e acomodado sobre uma estante. Foi assim que também o Programa da Peça quis se fazer cena impressa ao estampar páginas em branco, interpoladas a passagens do texto traduzido e passagens do texto cênico.

Para a questão central que se está discutindo, acredito poder concluir que esta experiência apresenta-se como caso oportuno para reflexão no âmbito dos estudos da genética teatral. Nela se verificou a sobreposição da realização de tradução com a de um dramaturgismo altamente determinado por exigências da cena (e da Companhia); diferentemente das experiências até $o$ momento apresentadas, nesta houve ocorrência de um movimento mais tradicionalmente linear entre as várias etapas da migração do texto teatral de origem para o texto cênico. $O$ que acabou por permitir, no entanto, o

Maria de Lourdes Rabetti, O Laboratório do Dramaturg e os Estudos de Genética Teatral: experimentos R.bras.est.pres., Porto Alegre, v.1, n.2, p. 443-458, jul./dez., 2011. 
florescimento de dois dados cênicos interessantes e insuspeitados, para o problema em questão: inicialmente, por não ter impedido, ao fim, que a última camada de tratamento cênico do forte e impositivo texto matricial fosse matizada pela mobilidade e fluidez da palavra proferida, pelas oralidades diversas que iam interferindo na tradução do texto e construindo a polifonia da cena; e depois, como se disse, por integrar a força da tradução do texto e da ação dramaturgista ao conjunto dos elementos mais expressivos do espetáculo teatral encenado.

\section{Da Palavra é Onde Nasce o Teatro}

A título de confronto, incluímos uma experiência de dramaturgismo pontual, fora do espaço de uma companhia permanente e para uma apresentação teatral de apenas dois dias. O presépio de Vieira: palavras para deleite e obras, adaptação e roteiro a partir do Sermão do Nascimento do Menino Deus, Sermão da Sexagésima e Sermão da Epifania, do Padre António Vieira foi à cena nos Encontros para as vésperas de Natal, realizados em dezembro de 1997, sob direção de Moacyr Góes, seis anos após o encerramento dos trabalhos da Companhia ${ }^{8}$. Constituiu-se em ação pontual, desencadeada a partir de convite da Prefeitura da Cidade do Rio de Janeiro (RioArte): ação cênica integrada a eventos natalinos. Para diretor e dramaturgista desta montagem o objetivo maior do evento era o de abrir as portas do Teatro Carlos Gomes, da Praça Tiradentes, emblema do teatro musicado brasileiro, para que participasse do conjunto das festas citadinas voltadas para o nascimento do menino deus. As intervenções de ordem temática nos Sermões de Vieira limitaram-se à seleção e combinação de algumas passagens de textos que refletissem o drama que viveu e que nos sermões expressou frente às muitas línguas novas com que se defrontava no Brasil. Com especial interesse para as que sugerissem articulações deste tenso campo de atritos entre linguagens com adversidades mais amplas que equacionam o estabelecimento de uma língua com a formação de uma nação. O Sermão da Sexagésima foi campo especialmente fértil onde colher estas passagens de textos com múltiplas imbricações. Ainda em campo

Maria de Lourdes Rabetti, O Laboratório do Dramaturg e os Estudos de Genética Teatral: experimentos R.bras.est.pres., Porto Alegre, v.1, n.2, p. 443-458, jul./dez., 2011. 
temático, pretendeu-se imbricar também o nascimento do menino divino com o mito de um país sempre jovem (só com futuro e sem passado) - país sempre criança. E ainda, circunstancial e politicamente referir, mesmo que de modo alegórico, ao massacre de crianças e jovens na praça da Candelária, situada no centro antigo da cidade, assim como o Teatro que participava dos festejos cívicos de natal.

Formalmente, o jogo entre texto e cena aproveitava o fato de se tratar de uma leitura dramatizada (todo o roteiro do Presépio foi literalmente lido em cena): colocação de uma leitura em ato, investimento forte e exclusivo na dramaticidade e na corporeidade das palavras de Vieira, procurando retirar da palavra proferida qualquer ênfase que já não fosse a própria do texto, texto que embutia a performance oratória, como sabemos. Para a discussão das migrações entre texto impresso e palavra proferida na cena do teatro, vale observar que a atriz (uma grande atriz do teatro brasileiro, Marília Pêra), seguindo as palavras do texto, procurava se fazer antes veículo condutor do que intérprete, como se falasse em nome do texto, lido folha após folha (algumas com uma única frase, outras em lauda completa). E que, lendo, cumpria seu papel, pois limitada ao espaço de pequeno púlpito, este era seu ato, o de ler em cena. E da leitura em ato, lirismo, tensões agudas, desespero, deleite e alegria, próprios dos Sermões, textos canônicos que bem sabiam das escritas e reescritas no vaivém da folha estampada à performance da voz. Ato de leitura cênica, portanto, que pretendeu explorar os movimentos próprios da oratória de Vieira, e inventou cortes para ligações abruptas, entre passagens de um mesmo sermão, entre os três sermões. Cortes e ligamentos em cena preenchidos com silêncios, ditos suaves, música instrumental sacra, cantos tradicionais da religiosidade popular no Brasil ${ }^{9}$. A única imagem de fundo de cena - um enorme painel branco, em alto-relevo, que pelo incidir das luzes ia desnudando a bandeira brasileira, com seu círculo central formado por ex-votos, que são feitos de corpos desmembrados - ali estava para realçar, na verdade, apenas à leitura de Vieira: sermão estilhaçado a serviço

Maria de Lourdes Rabetti, O Laboratório do Dramaturg e os Estudos de Genética Teatral: experimentos R.bras.est.pres., Porto Alegre, v.1, n.2, p. 443-458, jul./dez., 2011. 
da cena, que, por sua vez, se bastou com o mais puro deleite de sua leitura.

Compreendemos que o problema das migrações texto e cena, no Presépio de Vieira, poderá trazer alguma discussão de interesse para os estudos de genética teatral, exatamente porque poderia sugerir pouca intervenção no texto original, a começar pela ausência de tradução e, ao fim, por deixar as palavras de Vieira ocuparem de modo quase que exclusivo a cena de uma leitura. E, no entanto, a adaptação e o roteiro colheram e organizaram, ao seu modo, diversas passagens de diferentes textos do autor, acabando por lhes oferecer sentidos outros, alguns deles bastante atualizados. Mas, mesmo assim, pensamos que ainda mais sugestivo sinal em meio aos caminhos do texto à cena pode sobrevir da experiência de um teatro até mesmo de ocasião, de circunstância: o contentamento com apenas ler Vieira em cena permitiu concretizar cenicamente que as palavras deste autor ainda são obras e, assim, feitas para ouvir e para ver; palavras feitas para serem vistas podem desnortear até mesmo caminhos por demais conhecidos. E nos fez rememorar que a palavra é a origem da cena.

\section{Consideração Final}

Certamente o laboratório de dramaturgismo não faz de sua experiência qualquer escola de genética teatral; não seria próprio desta atuação e nem conveniente ao seu papel. Mas, sua presença, o espaço do seu trabalho, as ações que empreende no seio do processo criador - do texto à cena, da cena ao texto, e enquanto houver formas para deste trajeto se falar - tem muito a contribuir para ampliar nosso olhar a respeito das inúmeras trilhas por meio das quais este percurso ainda pode ser feito nos processos de construção cênica.

\footnotetext{
Notas

${ }^{1} \mathrm{O}$ texto tem origem em comunicação realizada no Colóquio Internacional "Percursos da genética teatral: do laboratório à escrita da cena", ocorrido em dezembro de 2009 na Universidade de Lisboa, em Portugal. Inseriu-se na linha programática dedicada à "Gênese cênica: percursos genéticos da criação teatral em função das reescritas para a

Maria de Lourdes Rabetti, O Laboratório do Dramaturg e os Estudos de Genética Teatral: experimentos R.bras.est.pres., Porto Alegre, v.1, n.2, p. 443-458, jul./dez., 2011. 
cena" e teve seu foco na "questão do dramaturg em ação: reconstrução da passagem do texto dramático à cena".

${ }^{2}$ Nosferatu - sinfonia de vida e morte teve argumento e roteiro elaborados por Moacyr Góes e Maria de Lourdes Rabetti, a partir da obra literária de Bram Stoker e dos filmes de Murnau e Herzog. O texto foi escrito por Janice Theodoro da Silva. Woyzeck constituiu a primeira experiência de tradução e adaptação para a cena realizada pela dramaturgista para esta Companhia. Os trabalhos de ensaio e encenação foram desenvolvidos do final de 1987 aos primeiros meses de 1988.

${ }^{3}$ Para Baal, de Brecht, optou-se pela tradução do encenador e professor de teatro, Luís Antônio Martinez Corrêa.

4 Certamente, esse conjunto de reconhecimentos teve também sua dimensão institucionalizada e consagrada pelas várias premiações e/ou indicações a prêmios, para o ano de 1988; melhor espetáculo, direção; o trabalho do dramaturg.

5 Os Gigantes da Montanha, de Luigi Pirandello, foram traduzidos por Rabetti, e levados à cena com inclusão do quarto ato, que Pirandello teria ditado ao filho em seu leito de morte, de autoria discutida.

${ }^{6}$ Do laboratório à escrita da cena foi tema de uma das linhas de ação do Colóquio Internacional onde se originou o presente ensaio, referido no início do texto.

${ }^{7}$ A tradução brasileira foi elaborada por Maria de Lourdes Rabetti, a partir da versão italiana em prosa de Maria Antonieta Andreoni D’Ovidio.

8 Após a dissolução da Companhia a dramaturgista voltou a trabalhar com Moacyr Góes, durante sua direção artística do Teatro Carlos Gomes, tendo atuado com esta função em três montagens, nos anos de 1997 e 1998, dentre elas este Presépio de Vieira.

9 Compunham a cena desta leitura dramática, a atriz Marília Pêra, a cantora Olivia Byington e o compositor Wagner Tiso.

\section{Referências}

CERTEAU, Michel de. A Invenção do Cotidiano. 1. artes de fazer. Tradução de Ephraim Ferreira Alves. Petrópolis: Vozes, 1999.

DELEUZE, Gilles; BENE, Carmelo. Superpositions. Paris: Minuit, 1979. (Ver no Brasil: DELEUZE, Gilles. Sobre teatro: um manifesto de menos; O esgotado. Tradução de Fátima Saadi. Rio de Janeiro: Jorge Zahar, 2010. P. 25-64.)

LÉVI-STRAUSS, Claude. A Ciência do Concreto. In: LÉVI-STRAUSS, Claude. O Pensamento Selvagem. Tradução de Maria Celeste da Costa e Souza e Almir de Oliveira Aguiar. São Paulo: Nacional, EdUSP, 1970. P. 19-55.

Maria de Lourdes Rabetti (Beti Rabetti) é professora da Universidade Federal do Estado do Rio de Janeiro e pesquisadora do CNPq.

E-mail: mlrabetti@gmail.com

Recebido em Agosto de 2011

Aprovado em Novembro de 2011

Maria de Lourdes Rabetti, O Laboratório do Dramaturg e os Estudos de Genética Teatral: experimentos R.bras.est.pres., Porto Alegre, v.1, n.2, p. 443-458, jul./dez., 2011.

Disponível em http://www.seer.ufrgs.br/presenca 